\title{
Studies on Severity, Comparative Preponderance, Cultural and Morphological Variability of Alternaria Species Causing Alternaria Blight of Yellow Sarson (Brassica campestris L. var. Yellow Sarson Prain)
}

\author{
Sunil Kumar ${ }^{1}$, R. B. Singh ${ }^{2}$ and R. C. Shakywar ${ }^{{ }^{*}}$ \\ ${ }^{1}$ AICRP on Soybean, School of Agricultural Sciences and Rural Development, Nagaland University, \\ Medziphema, Nagaland (797 106), India \\ ${ }^{2}$ Narendra Deva University of Agriculture and Technology, Kumarganj, Faizabad, Uttar Pradesh (224 229), India \\ ${ }^{3}$ College of Horticulture and Forestry, Central Agricultural University, Pasighat, Arunachal Pradesh (791 102), India
}

\section{Article History}

Manuscript No. AR1346

Received in $23^{\text {rd }}$ March, 2015

Received in revised form $18^{\text {th }}$ March, 2016

Accepted in final form $20^{\text {th }}$ April, 2016

\section{Correspondence to}

"E-mail: rcshakywar@gmail.com

\section{Keywords}

Alternaria brassicae, Alternaria brassicicola, yellow sarson, cultural, variability

\section{Introduction}

Rapeseed-mustard is the most important oilseed crops grown in north-eastern part of India. Among them yellow sarson is most important which have higher oil content. This crop is highly susceptible to Alternaria blight disease (Kolte et al., 1987). Among the various biotic diseases on this crop, Alternaria blight is caused by Alternaria brassicae (Berk.) Sacc and Alternaria brassicicola (Schwein) Wiltshire is most important and causes yield reduction up to $47 \%$ in Indian mustard (Chattopadhayay, 2008). There are number of workers have been reported on different aspects like cultural variability in Alternaria species in respect of mycelial growth and sporulation in different temperature, relative humidity and hydrogen ion concentration (Ansari et al., 1989), conidial length, width and septation in different region isolates (Khan et al., 2007) and conidial length and breadth, beak length and septation (transverse and longitudinal) (Goyal et al., 2011). Considering the importance of the crop, destructive nature of disease and unavailability of information the study was undertaken to investigate the severity of Alternaria blight, cultural and morphological variability and comparative preponderance of Alternaria brassicae and Alternaria brassicicola in different plant part isolates of ten yellow sarson entries.

\section{Materials and Methods}

The studies were conducted at the Student's Instructional Farm and Plant Pathology laboratory of the Narendra Deva University of Agriculture and Technology Kumarganj, Faizabad, India during rabi of 2006-07 and 2007-08. A trial consisting of 10 yellow sarson entries namely YST 151, NDYS 
2 , NDYS 117, NDYS 123, NDYS 2018, NDYS 116-1, NDYS 107 , NDYS 119, NDYS 115-1 and NDYS 132-2 were planted on 20 October, 30 October and 10 November during 200607 and 2007-08 to investigate the first initiation, maximum severity of Alternaria blight, comparative preponderance of Alternaria brassicae and Alternaria brassicicola, cultural and morphological variability. Ten plants in each plot were randomly selected and tagged. Alternaria blight severity was measured visually as per cent affected area on lower, middle and upper leaves following 0-5 scale (Conn et al., 1990). Reading were averaged to calculate the per cent disease intensity $(\mathrm{PDI})=[$ Total numerical rating/Total number of observations taken $\times$ Highest disease score $] \times 100$ (Van der Plank, 1963).

Arial part of yellow sarson plants showing typical blight symptoms on leaf, stem and pods were collected from experimental fields randomly at 75, 90 and 105 days after sowing. The samples were kept in rough dry paper envelops, especially meant for the purpose. The samples maintained for the purpose were taken up, separately for isolation. These were washed using sterilized water and cut into small pieces by sterilized scalpel and forceps. These pieces were surface sterilized with $0.1 \% \mathrm{H}_{\mathrm{g}} \mathrm{Cl}_{2}$ solution and washed thoroughly three to four times with sterilized water. These were demoisturized by placing them between folds of sterilized blotting papers and transferred aseptically to Petri dishes containing potato dextrose agar medium. On initiation of the mycelium growth around these pieces, the hyphal tips from the advancing mycelia were cut using cork borer and transferred into potato dextrose agar slants for further study. The pure culture of the isolates was obtained through single spore isolation technique.

A total of 30 mono-conidial isolates, each entry from leaf, stem and pods (10 from each part) were selected for the variability studies. Temporary slides were prepared, using lectophenol from 10 days old cultures. Slides were examined with the help of a binocular compound microscope under low and high magnification. Observations were recorded for colony diameter, length, width, size and number of septa in the conidiophores and conidia of individual isolates. To maintain uniformity, 50 counts were made and data averaged. For per cent frequency of isolation of individual species, a total of 300 isolates, 10 each from leaf, stem and pods of 10 yellow sarson entries were obtained and calculate the frequencies.

\section{Results and Discussion}

\subsection{Effect of date of sowing}

The initial symptoms of Alternaria blight was noted on 09 December and 11 December during 2006-07 and 2007-08 in the entry NDYS 2 attaining highest PDI of 69.90 and $75.40 \%$, respectively in 20 October sown crop (Table 1). In
30 October sown crop the disease initiation was noted on 03 and 15 December during 2006-07 and 2007-08 on same entry. However, in $10^{\text {th }}$ November sown crop the initiation of disease was noted on $18^{\text {th }}$ December during 2006-07 in the entries YST 151, NDYS 2 and NDYS 115-1 attaining highest PDI of $64.80,66.80$ and $57.45 \%$, respectively and during 2007-08 it appeared on 19 December in NDYS 107 attaining highest PDI of $63.00 \%$. In general the initiation of Alternaria blight in 20 October sown crop was noted after 50 to 54 days and 52 to 56 days after sowing during 2006-07 and 2007-08 and duration to attain highest PDI was noted 52 to 56 days and 53 to 55 days of its initiation, respectively. In $30^{\text {th }}$ October sown crop the initiation of disease was noted after 44 to 49 days and 46 to 50 days after sowing and highest PDI attained after 51 to 53 days and 51 to 54 days of its initiation during both the years, respectively, while the crop sown on 10 November the appearance of disease was noted after 38 to 42 days and 39 to 43 days after sowing and highest PDI attained after 48 to 51 days and 49 to 52 days from the initiation during both the years. Maximum disease intensity was noted in $30^{\text {th }}$ October sown crop and minimum in 10 November during both the years of testing. Date of sowing had substantial effect on the intensity of Alternaria blight. In accordance with present findings Singh and Singh (2006) also reported the highest mean disease intensity in $30^{\text {th }}$ October sown Indian mustard. Gupta et al. (2003) reported increasing blight intensity with delayed sowing in case of rapeseed and mustard. But as against subsequent decline in blight intensity after $20^{\text {th }}$ December at Pantnagar, decline in our case in case of yellow sarson set in the $10^{\text {th }}$ November sown crop itself.

\subsection{Colony diameter}

In general colony diameter of $A$. brassicicola was found higher in comparison to A. brassicae in case of each affected parts (Table 2). Part wise, the maximum average colony diameter of $A$. brassicae and A. brassicicola was found in case of leaves ( $30.70 \mathrm{~mm}$ with range of $25-38 \mathrm{~mm}$ and 33.40 $\mathrm{mm}$ with range of $27-42 \mathrm{~mm})$ followed by pods $(28.60 \mathrm{~mm}$ with range of $23-35 \mathrm{~mm}$ and $30.80 \mathrm{~mm}$ with range of 25 $34 \mathrm{~mm}$ ) and stem (26.80 mm with range of $20-34 \mathrm{~mm}$ and $28.40 \mathrm{~mm}$ with range of 23-36 mm), respectively (Table 2). Among the entries average maximum colony diameter of $A$. brassicae was noted in NDYS $2018(35.67 \mathrm{~mm})$ with range of 34-38 $\mathrm{mm}$ followed by NDYS $123(34.67 \mathrm{~mm})$ with range of 33-37 mm and NDYS $2(34.33 \mathrm{~mm})$ with range of 32$36 \mathrm{~mm}$. Minimum colony diameter of $22.67 \mathrm{~mm}$ with range of 20-25 mm was noted in NDYS 132-2. Similar trend was recorded in case of $A$. brassicicola.

\subsection{Conidiophore}

In general the conidiophores of $A$. brassicae were found lengthiest in comparison to A. brassicicola in case of each 


\begin{tabular}{|c|c|c|c|c|c|c|c|c|c|c|c|c|}
\hline \multirow[t]{3}{*}{ Entries } & \multicolumn{3}{|c|}{ Date of initiation } & \multicolumn{3}{|c|}{$\begin{array}{c}\text { Date of highest disease } \\
\text { intensity }\end{array}$} & \multicolumn{3}{|c|}{$\begin{array}{l}{ }^{*} \text { DHDI from the date } \\
\text { of initiation }\end{array}$} & \multicolumn{3}{|c|}{$\begin{array}{l}\text { Highest disease } \\
\text { intensity }(\%)\end{array}$} \\
\hline & $\mathrm{D}_{1}$ & $\mathrm{D}_{2}$ & $\mathrm{D}_{3}$ & $\mathrm{D}_{1}$ & $\mathrm{D}_{2}$ & $\mathrm{D}_{3}$ & $\mathrm{D}_{1}$ & $\mathrm{D}_{2}$ & $\mathrm{D}_{3}$ & $\mathrm{D}_{1}$ & $\mathrm{D}_{2}$ & $\mathrm{D}_{3}$ \\
\hline & \multicolumn{12}{|c|}{ 2006-07 } \\
\hline $\begin{array}{l}\text { YST } \\
151\end{array}$ & $\begin{array}{l}11.12 .06 \\
(52)\end{array}$ & $\begin{array}{l}13.12 .06 \\
(44)\end{array}$ & $\begin{array}{l}18.12 .06 \\
(38)\end{array}$ & 02.02 .07 & 03.02 .07 & 06.02 .07 & 53 & 52 & 50 & 67.72 & 72.80 & 64.80 \\
\hline $\begin{array}{l}\text { NDYS } \\
2\end{array}$ & $\begin{array}{l}09.12 .06 \\
\quad(50)\end{array}$ & $\begin{array}{l}13.12 .06 \\
(44)\end{array}$ & $\begin{array}{l}18.12 .06 \\
(38)\end{array}$ & 30.01 .07 & 02.02 .07 & 04.02 .07 & 52 & 51 & 48 & 69.90 & 75.55 & 66.80 \\
\hline $\begin{array}{l}\text { NDYS } \\
117\end{array}$ & $\begin{array}{l}14.12 .06 \\
(55)\end{array}$ & $\begin{array}{l}16.12 .06 \\
(47)\end{array}$ & $\begin{array}{l}22.12 .06 \\
(42)\end{array}$ & 05.02 .07 & 05.02 .07 & 09.02 .07 & 53 & 51 & 49 & 59.95 & 67.35 & 60.52 \\
\hline $\begin{array}{l}\text { NDYS } \\
123\end{array}$ & $\begin{array}{l}11.12 .06 \\
(52)\end{array}$ & $\begin{array}{l}16.12 .06 \\
(47)\end{array}$ & $\begin{array}{l}20.12 .06 \\
\quad(40)\end{array}$ & 01.02 .07 & 05.02 .07 & 07.02 .07 & 52 & 51 & 49 & 61.40 & 68.30 & 63.27 \\
\hline $\begin{array}{l}\text { NDYS } \\
2018\end{array}$ & $\begin{array}{l}09.12 .06 \\
(50)\end{array}$ & $\begin{array}{l}13.12 .06 \\
(44)\end{array}$ & $\begin{array}{l}20.12 .06 \\
(40)\end{array}$ & 30.01 .07 & 02.02 .07 & 07.02 .07 & 52 & 51 & 49 & 69.85 & 77.32 & 66.82 \\
\hline $\begin{array}{l}\text { NDYS } \\
116-1\end{array}$ & $\begin{array}{l}13.12 .06 \\
(54)\end{array}$ & $\begin{array}{c}17.12 .06 \\
(48)\end{array}$ & $\begin{array}{l}21.12 .06 \\
(41)\end{array}$ & 04.02 .07 & 07.02 .07 & 09.02 .07 & 53 & 52 & 50 & 56.90 & 62.32 & 59.25 \\
\hline $\begin{array}{l}\text { NDYS } \\
107\end{array}$ & $\begin{array}{l}14.12 .06 \\
(55)\end{array}$ & $\begin{array}{l}16.12 .06 \\
(47)\end{array}$ & $\begin{array}{l}19.12 .06 \\
(39)\end{array}$ & 05.02 .07 & 05.02 .07 & 07.02 .07 & 53 & 51 & 50 & 61.25 & 68.30 & 60.85 \\
\hline $\begin{array}{l}\text { NDYS } \\
119\end{array}$ & $\begin{array}{l}14.12 .06 \\
(55)\end{array}$ & $\begin{array}{l}19.12 .06 \\
(49)\end{array}$ & $\begin{array}{l}22.12 .06 \\
(42)\end{array}$ & 07.02 .07 & 10.02 .07 & 11.02 .07 & 55 & 53 & 51 & 51.35 & 57.95 & 53.70 \\
\hline $\begin{array}{l}\text { NDYS } \\
115-1\end{array}$ & $\begin{array}{l}13.12 .06 \\
(54)\end{array}$ & $\begin{array}{l}15.12 .06 \\
(46)\end{array}$ & $\begin{array}{l}18.12 .06 \\
(38)\end{array}$ & 04.02 .07 & 05.02 .07 & 06.02 .07 & 53 & 52 & 50 & 52.95 & 60.00 & 57.45 \\
\hline $\begin{array}{l}\text { NDYS } \\
132-2\end{array}$ & $\begin{array}{l}13.12 .06 \\
(54)\end{array}$ & $\begin{array}{c}16.12 .06 \\
(47)\end{array}$ & $\begin{array}{l}19.12 .06 \\
(39)\end{array}$ & 05.02 .07 & 07.02 .07 & 07.02 .07 & 54 & 53 & 50 & 56.30 & 64.37 & 58.35 \\
\hline \multicolumn{13}{|c|}{ 2007-08 } \\
\hline $\begin{array}{l}\text { YST } \\
151\end{array}$ & $\begin{array}{l}12.12 .07 \\
(53)\end{array}$ & $\begin{array}{l}15.12 .07 \\
(46)\end{array}$ & $\begin{array}{l}20.12 .07 \\
\quad(40)\end{array}$ & 04.02 .08 & 06.02 .08 & 08.02 .08 & 54 & 53 & 50 & 70.80 & 74.93 & 65.85 \\
\hline $\begin{array}{l}\text { NDYS } \\
2\end{array}$ & $\begin{array}{c}11.12 .07 \\
(52)\end{array}$ & $\begin{array}{c}15.12 .07 \\
(46)\end{array}$ & $\begin{array}{l}20.12 .07 \\
\quad(40)\end{array}$ & 02.02 .08 & 05.02 .08 & 07.02 .08 & 53 & 52 & 49 & 75.40 & 78.02 & 67.90 \\
\hline $\begin{array}{l}\text { NDYS } \\
117\end{array}$ & $\begin{array}{l}12.12 .07 \\
(53)\end{array}$ & $\begin{array}{c}16.12 .07 \\
(47)\end{array}$ & $\begin{array}{l}22.12 .07 \\
(42)\end{array}$ & 05.02 .08 & 07.02 .08 & 10.02 .08 & 55 & 53 & 50 & 68.80 & 72.37 & 62.65 \\
\hline $\begin{array}{l}\text { NDYS } \\
123\end{array}$ & $\begin{array}{c}13.12 .07 \\
(54)\end{array}$ & $\begin{array}{c}17.12 .07 \\
(48)\end{array}$ & $\begin{array}{c}22.12 .07 \\
(42)\end{array}$ & 04.02 .08 & 06.02 .08 & 09.02 .08 & 53 & 51 & 50 & 71.25 & 75.83 & 66.10 \\
\hline $\begin{array}{l}\text { NDYS } \\
2018\end{array}$ & $\begin{array}{c}11.12 .07 \\
(52)\end{array}$ & $\begin{array}{c}16.12 .07 \\
(47)\end{array}$ & $\begin{array}{c}22.12 .07 \\
(42)\end{array}$ & 02.02 .08 & 07.02 .08 & 09.02 .08 & 53 & 51 & 49 & 76.65 & 77.95 & 68.95 \\
\hline $\begin{array}{l}\text { NDYS } \\
116-1\end{array}$ & $\begin{array}{c}12.12 .07 \\
(53)\end{array}$ & $\begin{array}{c}17.12 .07 \\
(48)\end{array}$ & $\begin{array}{c}22.12 .07 \\
(42)\end{array}$ & 04.02 .08 & 08.02 .08 & 10.02 .08 & 54 & 53 & 50 & 67.80 & 71.36 & 61.79 \\
\hline $\begin{array}{l}\text { NDYS } \\
107\end{array}$ & $\begin{array}{c}12.12 .07 \\
(53)\end{array}$ & $\begin{array}{c}15.12 .07 \\
(46)\end{array}$ & $\begin{array}{c}19.12 .07 \\
(39)\end{array}$ & 03.02 .08 & 05.02 .08 & 07.02 .08 & 53 & 52 & 50 & 66.35 & 70.75 & 63.00 \\
\hline $\begin{array}{l}\text { NDYS } \\
119\end{array}$ & $\begin{array}{c}15.12 .07 \\
(56)\end{array}$ & $\begin{array}{c}19.12 .07 \\
(50)\end{array}$ & $\begin{array}{c}23.12 .07 \\
\quad(43)\end{array}$ & 08.02 .08 & 11.02 .08 & 13.02 .08 & 55 & 54 & 52 & 59.05 & 64.25 & 56.85 \\
\hline $\begin{array}{l}\text { NDYS } \\
115-1\end{array}$ & $\begin{array}{c}14.12 .07 \\
(55)\end{array}$ & $\begin{array}{c}16.12 .07 \\
(47)\end{array}$ & $\begin{array}{c}20.12 .07 \\
(40)\end{array}$ & 05.02 .08 & 06.02 .08 & 09.02 .08 & 53 & 52 & 51 & 65.00 & 69.10 & 60.90 \\
\hline $\begin{array}{l}\text { NDYS } \\
132-2\end{array}$ & $\begin{array}{c}13.12 .07 \\
(54)\end{array}$ & $\begin{array}{c}16.12 .07 \\
(47)\end{array}$ & $\begin{array}{c}21.12 .07 \\
(41)\end{array}$ & 04.02 .08 & 07.02 .08 & 11.02 .08 & 53 & 53 & 52 & 67.72 & 70.35 & 63.85 \\
\hline
\end{tabular}

Figure in parentheses are days after sowing; $\mathrm{D}_{1}: 20^{\text {th }}$ Oct; $\mathrm{D}_{2}: 30$ Oct; $\mathrm{D}_{3}: 10^{\text {th }}$ Nov.; ${ }^{*}$ DHDI: Days to highest disease intensity 
affected parts. Average lengthiest conidiophores of $A$. brassicae and A. brassicicola was found in case of leaves (64.04 $\mu$ and $39.68 \mu)$ followed by pod $(62.11 \mu$ and 37.46 $\mu)$ and stem $(58.64 \mu$ and $36.33 \mu)$, respectively. Among the entries average maximum length of conidiophores of $A$. brassicae was noted in the isolates of NDYS $2018(71.24 \mu$ with range of 68.89-73.92 $\mu$ followed by NDYS 123 (67.65 $\mu)$ with range of 64.36-70.19 $\mu$ and NDYS $2(65.71 \mu)$ with range of 59.91-70.31 $\mu$. Shortest conidiophore of $55.48 \mu$ was found in NDYS 119. Lengthiest conidiophores of $A$. brassicicola was also noted in same entry i.e. NDYS 2018 $(41.70 \mu)$ followed by NDYS $2(41.47 \mu)$ and YST 151 $(41.20 \mu \mu)$. Shortest conidiophore of A. brassicicola was found in NDYS 132-2 $(34.69 \mu \mu)$. Conidiophores length of A. brassicae isolates obtained from leaves ranged between $56.67 \mu$ (NDYS 119) to $73.92 \mu$ (NDYS 2018), from stem between $53.79 \mu$ (NDYS 119) to $68.89 \mu$ (NDYS 2018) and from pods between $55.97 \mu$ (NDYS 119) to $70.91 \mu$ (NDYS 2018), respectively. Conidiophores length of $A$. brassicicola obtained from leaves ranged between $35.60 \mu$ (NDYS 132-2) to $46.39 \mu$ (YST 151), from stem between $33.69 \mu$ (NDYS 132-2) to $40.69 \mu$ (NDYS 2018) and from pods between $33.75 \mu$ (NDYS 117) to $41.79 \mu$ (NDYS 2018), respectively.

In general the conidiophores of $A$. brassicae were widest in comparison to A. brassicicola in case of each affected parts. Average widest conidiophores of $A$. brassicae and $A$. brassicicola was found in case of leaves $(6.49 \mu$ and 5.18 $\mu)$ followed by pod $(5.77 \mu$ and $4.69 \mu)$ and stem $(5.10 \mu$ and $4.50 \mu$ ), respectively. In case of entries, average widest conidiophores of A. brassicae was noted in NDYS 2018 (7.71 $\mu)$ followed by NDYS $107(6.91 \mu)$ and NDYS $2(5.94 \mu)$. Narrowest conidiophore of $4.30 \mu$ was noted in NDYS 132-2. Widest conidiophores of $A$. brassicicola was noted in NDYS $107(5.72 \mu)$ followed by NDYS $2018(5.60 \mu)$ and NDYS $2(5.14 \mu)$. Narrowest conidiophore of $A$. brassicicola was noted in NDYS 132-2 (3.65 $\mu)$. Conidiophores width of $A$. brassicae isolates obtained from leaves ranged between 4.71 to $8.10 \mu$, from stem between 4.01 to $7.11 \mu$ and from pods 4.19 to $7.91 \mu$ in NDYS $132-2$ and NDYS 2018, respectively. Conidiophores width of $A$. brassicicola obtained from leaves also ranged between $3.91 \mu$ (NDYS 132-2) to $5.72 \mu$ (NDYS 2), from stem between $3.41 \mu$ (NDYS 132-2) to $6.29 \mu$ (NDYS 107) and from pods between $3.64 \mu$ (NDYS 132-2) to $5.91 \mu$ (NDYS 2018).

More septation was recorded in conidia of $A$. brassicae isolates in comparison to A. brassicicola obtained from different affected parts. Average maximum septation was recorded in conidiophores of $A$. brassicae and A. brassicicola obtained from leaves ( 6.90 and 5.20) followed by pods (5.90 and 4.80) and stem (4.90 and 3.90), respectively. Among the entries mean maximum number of septa in $A$. brassicae was noted in the conidiophores of NDYS 2018 (7.00) followed by
NDYS 123 (6.67) and YST 151 (6.00). Minimum septation of 4.33 was noted in conidiophores of NDYS 119. Similar trend was recorded in septation of conidiophores of $A$. brassicicola also in test entries. Number of septa in conidiophores of $A$. brassicae obtained from leaves ranged between 5 (NDYS 119) to 8 (NDYS 2018), from stem between 4 (NDYS 119) to 6 (NDYS 2018) and from pods between 4 (NDYS 119) to 7 (NDYS 2 and NDYS 2018). While in case of A. brassicicola septation in conidiophores of leaves ranged between 4 (NDYS 119) to 7 (NDYS 2018), in stem between 3 (YST 151, NDYS 2 and NDYS 119) to 5 (NDYS 2018 and NDYS 107) and in pods between 4 (NDYS 2, NDYS-119 and NDYS 115-1) to 5 (NDYS 2018 and NDYS 107).

\subsection{Conidia}

In general the conidial length of $A$. brassicae was found more in comparison to A. brassicicola in case of each affected parts. Average lengthiest conidia of A. brassicae and $A$. brassicicola was noted in case of leaves $(169.29 \mu$ and 52.19 $\mu)$ followed by pod $(148.08 \mu$ and $47.76 \mu)$ and stem (127.76 $\mu$ and $44.95 \mu)$ respectively. Among the entries average lengthiest conidia of A. brassicae was noted in NDYS 2018 $(160.45 \mu)$ followed by NDYS $2(160.21 \mu)$ and YST 151 $(157.41 \mu)$. Shortest conidia of $A$. brassicae $(137.63 \mu)$ was noted in NDYS 119. Lengthiest conidia of A. brassicicola was also noted in NDYS $2018(50.73 \mu)$ followed by NDYS $115-1(49.55 \mu)$ and NDYS $2(49.46 \mu)$. Shortest conidia of A. brassicicola was noted in NDYS $107(45.57 \mu)$. Length of A. brassicae conidia obtained from leaves ranged between $155.75 \mu$ (NDYS 132-2) to $189.67 \mu$ (NDYS 2018), from stem between $115.38 \mu$ (NDYS 115-1) to $137.16 \mu$ (NDYS 2) and from pods between $135.36 \mu$ (NDYS 119) to 160.69 $\mu$ (NDYS 2018). Length of $A$. brassicicola conidia obtained from leaves ranged between $48.13 \mu$ (NDYS 107) to $56.30 \mu$ (NDYS 2018), from stem between $42.45 \mu$ (NDYS 119) to $47.39 \mu$ (NDYS 2) and from pods between $45.67 \mu$ (NDYS 107 ) to $49.67 \mu$ (NDYS 2), respectively (Table 2).

In general width of Alternaria brassicae was noted maximum in comparison to $A$. brassicicola in case of all affected plant parts. Average maximum conidial width of $A$. brassicae and A. brassicicola was noted in case of leaves $(20.57 \mu$ and 12.60 $\mu)$ followed by pods $(19.11 \mu$ and $11.59 \mu)$ and stem $(14.74 \mu$ and $10.93 \mu$ ), respectively. Among the entries average widest conidia of $A$. brassicae was noted in NDYS $2018(21.48 \mu)$ followed by NDYS 115-1 (20.68 $\mu$ ) and NDYS 132-2 (20.62 $\mu)$. Narrowest conidium was found in the NDYS 117 (16.90 $\mu)$. Widest conidia of A. brassicicola was found in NDYS $2018(12.87 \mu)$ followed by NDYS $2(12.66 \mu)$ and NDYS $123(12.42 \mu)$. Narrowest conidium of A. brassicicola was 


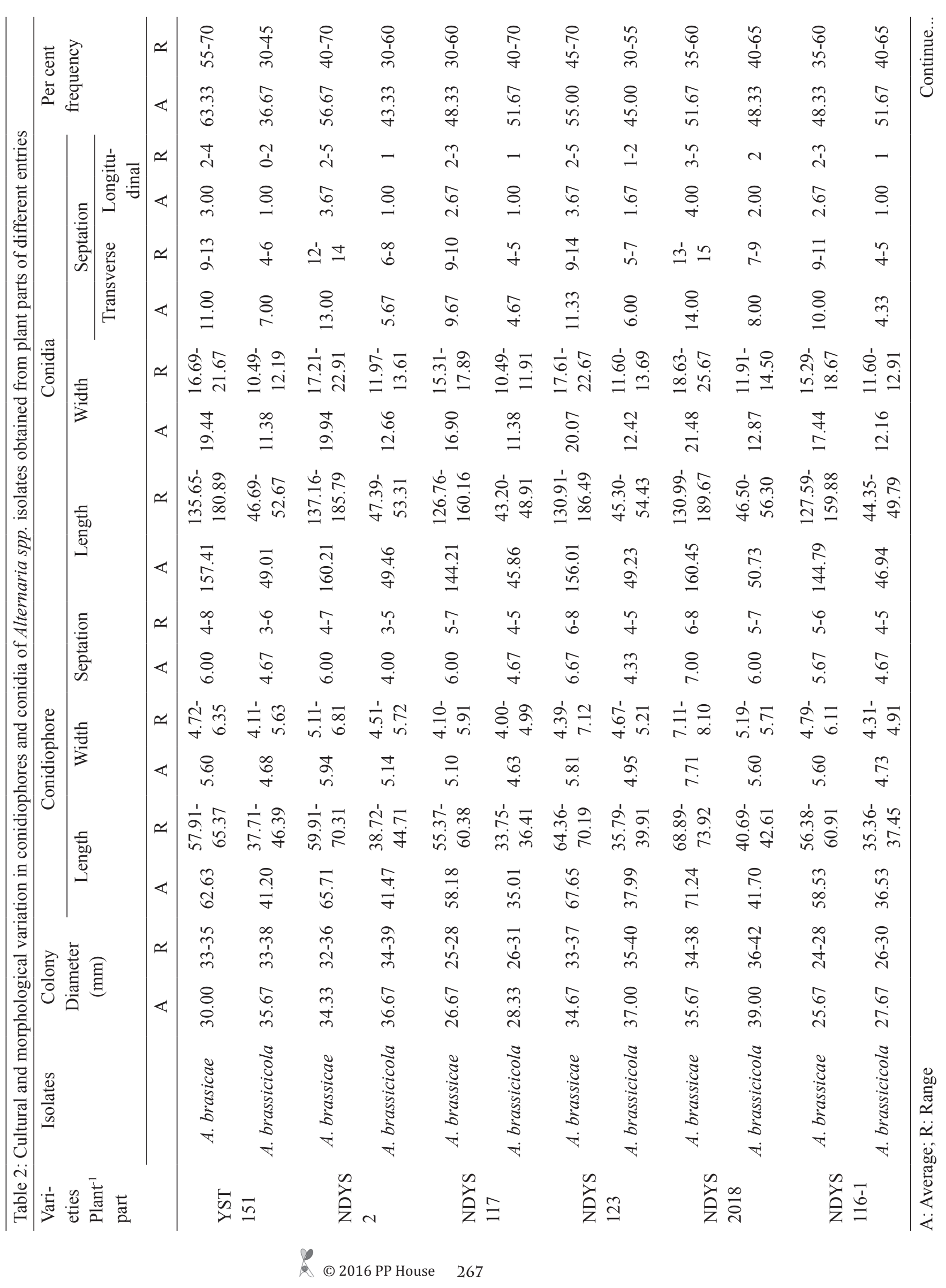




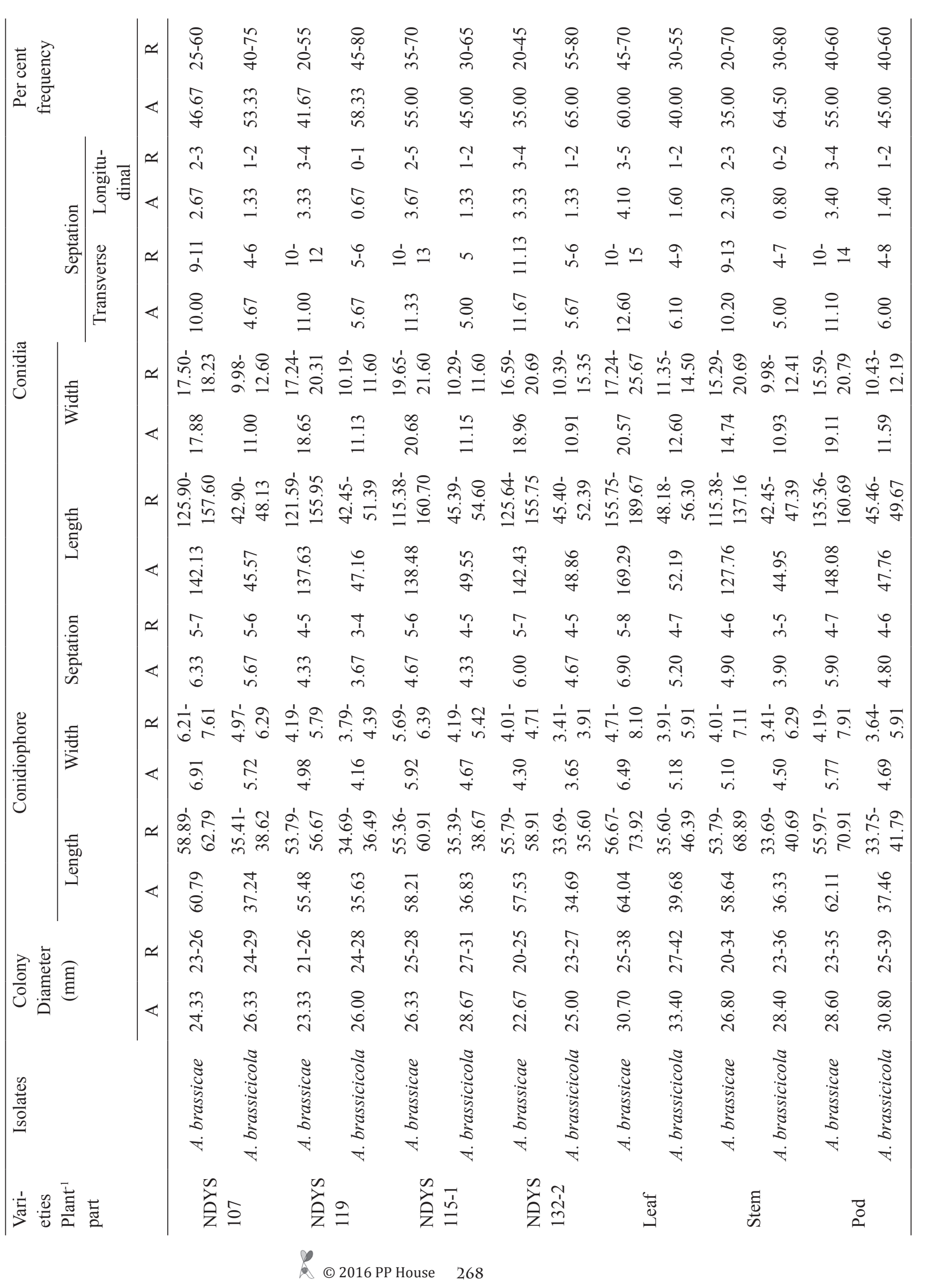


obtained from NDYS 132-2 (10.91 $\mu)$. Width of conidia of A. brassicae obtained from leaves ranged between $17.24 \mu$ (NDYS 119) to $25.67 \mu$ (NDYS 2018), from stem between $15.29 \mu$ (NDYS 116-1) to $19.65 \mu$ (NDYS 115-1) and from pods between $16.59 \mu$ (NDYS 132-2) to $20.79 \mu$ (NDYS 115 1). Conidial width of $A$. brassicicola obtained from leaves ranged between $11.35 \mu$ (NDYS 132-2) to $14.50 \mu$ (NDYS 2018), from stem between $9.98 \mu$ (NDYS 107) to $12.41 \mu$ (NDYS 2) and from pods between $10.43 \mu$ (NDYS 107) to $12.19 \mu$ (NDYS 2018).

Number of transverse septa in the conidia of $A$. brassicae was found maximum in comparison to $A$. brassicicola in case of each affected plant parts. Average maximum number of septa in conidia of $A$. brassicae and A. brassicicola was noted in case of leaves (12.60 and 6.10) followed by pods (11.10 and 6.00) and stem (10.20 and 5.00), respectively. Among the entries average highest number of septa in A. brassicae was noted in NDYS 2018 (14.00) followed by NDYS 2 (13.00). The lowest number of septa was found in NDYS 117 (9.67). Highest number of septa in A. brassicicola was noted in NDYS 2018 (8.00) followed by YST 151 (7.00). Lowest number of septa in A. brassicicola was found in NDYS 1161 (4.33). The number of septa in $A$. brassicae obtained from leaves range between 10 (NDYS 117) to 15 (NDYS 2018), from stem between 9 (YST 151) to 13 (NDYS 2018) and from pods between 10 (NDYS 117, NDYS 116-1, NDYS 107 and NDYS 119) to 14 (NDYS 2018). Likewise, the number of septa in A. brassicicola obtained from leaves ranged between 4 (NDYS 107) to 9 (NDYS 2018), from stem between 4 (YST 151, NDYS 117, NDYS 116-1 and NDYS 107) to 7 (NDYS 2018) and from pods ranged between 4 (NDYS 116-1) to 8 (NDYS 2018).

Longitudinal septation in conidia of $A$. brassicae was also found maximum in comparison to A. brassicicola in all the affected plant parts. Average maximum number of septa in A. brassicae and A. brassicicola was noted in case of leaves (4.10 and 1.60) followed by pods (3.40 and 1.40) and stem (2.30 and 0.80 ) respectively. Among the entries the average maximum number of septa in $A$. brassicae was noted in NDYS 2018 (4.00) followed by NDYS 123 (3.67). Minimum number of septa was found 2.67 in the entries NDYS 117 , NDYS 116-1 and NDYS 107. The maximum number of septa in A. brassicicola was noted in NDYS 2018 (2.00) followed by NDYS 123 (1.67) and NDYS 107 (1.33). Minimum number of septa was found in NDYS 119 (0.67). Longitudinal septa of $A$. brassicae isolates obtained from leaves ranged between 3-5 from stem between 2-3 and from pods 3-4. The longitudinal septa of $A$. brassicicola obtained from leaves also ranged between 1 to 2 , from stem 0 to 2 and from pods between 1 to 2, respectively (Table 2). Mehta et al. (2003) worked on the morphological and pathological variations in rapeseed-mustard isolates of $A$. brassicae collected from different agro climatic zone of India. They also reported variations in spore length and breadth and indicated the existence of variability in the pathogen. Singh et al. (2003) also reported the variation in colony growth, colour, size of conidia and conidiophores in case of Alternaria triticina causing leaf blight in wheat. Khan et al. (2007) isolated Alternaria brassicae with the samples collected from different places of Aligarh district and also reported variation in conidial length (112.0 to $185.6 \mu)$, breadth (14.4 to $17.6 \mu)$ and septation (5-16). The variation in colony colour, growth, colony size, length and breadth of conidiophore, length and breadth of conidia, vertical and horizontal septation in case of A. brassicae and A. brassicicola in present studies support the views of earlier workers. The studies therefore, also indicate the existence of variability among the isolates of $A$. brassicae and $A$. brassicicola obtained from yellow sarson, in eastern Uttar Pradesh.

3.5. Per cent frequency of A. brassicae and A. brassicicola obtained from leaves, stems and pods

On mean basis frequency of occurrence of $A$. brassicae was found maximum in case of leaves isolates followed by pods and stems. But in case of YST 151 frequency of $A$. brassicae was found more in stem followed by leaf and pod, while in NDYS 119 it was higher in pod followed by leaf and stem. Among the entries average maximum frequency of $A$. brassicae was noted in YST $151(63.33 \%)$ followed by NDYS 2 (56.67\%) and NDYS 123 (55.00\%). Minimum frequency of this pathogen was found in NDYS 132-2 (35.00 $\%$ ). Maximum mean per cent frequency of $A$. brassicicola was found in NDYS 132-2 (65.00\%) followed by NDYS 119 (58.33\%) and NDYS 107 (53.33\%) and minimum in YST 151 (36.67\%). Frequency of occurrence of $A$. brassicae obtained from leaves isolates ranged between $45 \%$ (NDYS 132-2) to 70\% (NDYS 2, NDYS 123 and NDYS 151-1), from stem between 20\% (NDYS 119 and NDYS 132-2) to $70 \%$ (YST 151) and from pods between $40 \%$ (NDYS 132-2) to $60 \%$ (NDYS 2, NDYS 107, NDYS 117 and NDYS $115-$ 1) respectively, while the frequency of $A$. brassicicola was recorded 30\% (NDYS 2, NDYS 123 and NDYS 115-1) to $55 \%$ (NDYS 132-2) from leaves isolates, 30\% (YST 151) to $80 \%$ (NDYS 119 and NDYS 132-2) from stem isolates and $40 \%$ (NDYS 2, NDYS 117, NDYS 107, NDYS 115-1 and NDYS 2018) to $60 \%$ (NDYS 132-2) from pod isolates, respectively.

\section{Conclusion}

NDYS 119 showed lowest disease severity during both the 
years which proved the least susceptibility. The frequency of occurrence of $A$. brassicae was found maximum in case of leaves isolates followed by pods and stems. However, the frequency of $A$. brassicicola was found maximum in case of isolates stem isolates followed by leaves and pods. Among the entries average maximum frequency of $A$. brassicae was noted in YST 151 followed by NDYS 2.

\section{References}

Ansari, N.A., Khan, M.W., Muheet, A., 1989. Effect of some factors on growth and sporulation of Alternaria brassicae causing Alternaria blight of rapeseed and mustard. Acta Botanika Indica 17(1), 49-53.

Chattopadhyay, C., 2008. Management of diseases of rapeseedmustard with special reference to Indian conditions. In: Kumar, A., Chauhan, J.S., Chattopadhyay, C. (Eds.), Sustainable Production of Oilseeds: Rapeseed-Mustard Tchnology. Agrotech Publishing Academy, Udaipur, 364-88.

Conn, K.L., Tewari, J.P., Awasthi, R.P., 1990. A disease assessment key far Alternaria black spot in rapeseed and mustard. Canadian Plant Disease Survey 70, 19-22.

Goyal, P., Chahar, M., Mathur, A.P., Kumar, A., Chattopadhyay, C., 2011. Morphological and cultural variation in different oilseed Brassica isolates of Alternaria brassicae from different geographical regions of India. Indian Journal of Agricultural Science 81(11), 1053-1058.
Gupta, R., Awasthi, R.P., Kolte, S.J., 2003. Influence of sowing dates and weather factors on development of Alternaria blight on rapeseed-mustard. Indian Phytopath 56(4), 398-402.

Khan, M.M., Khan, R.U., Mohiddin, F.A., 2007. Variation in occurrence and morphology of Alternaria brassicae (Berk.) Sacc. causing blight in rapeseed and mustard. Annals of plant protection science 15(2), 414-417.

Kolte, S.J., Awasthi, R.P., Vishwanath, 1987. Assessment of yield losses due to Alternaria blight in rapeseed and mustard. Indian Phytipath 40, 209-211.

Mehta, N., Sangwan, M.S., Srivastava, M.P., 2003. Morphological and pathological variation in rapeseed and mustard isolates of Alternaria brassicae. Indian Phytopath 56(2), 188-190.

Singh, R.B., Singh, R.N., 2006. Spray schedule for the management of Alternaria blight and white rust of Indian mustard (Brassica juncea) under different dates of sowing. Indian Journal of Agrilcultural Science 76(9), 575-579.

Singh, R.P., Singh, A.K., Singh, R.N., 2003. Pathogenic variability in Alternaria triticina causing leaf blight of wheat. Annals of plant protection science 11(2), 309311.

Van der Plank, J.E., 1963. Plant Disease: Epidamics and control. Academic Press, New York, London, 349. 